\title{
Comparative transcriptomic analysis of streptococcus pseudopneumoniae with viridans group streptococci
}

Hee Kuk Park', Soon Chul Myung ${ }^{2}$ and Wonyong Kim ${ }^{1 *}$

\begin{abstract}
Background: Streptococcus pseudopneumoniae, is a novel member of the genus Streptococcus, falling close to related members like S. pneumoniae, S. mitis, and S. oralis. Its recent appearance has shed light on streptococcal infections, which has been unclear till recently. In this study, the transcriptome of S. pseudopneumoniae CCUG $49455^{\top}$ was analyzed using the S. pneumoniae R6 microarray platform and compared with those of S. pneumoniae KCTC $5080^{\top}$, S. mitis KCTC $3556^{\top}$, and S. oralis KCTC $13048^{\top}$ strains.

Results: Comparative transcriptome analysis revealed the extent of genetic relatedness among the species, and implies that S. pseudopneumoniae is the most closely related to S. pneumoniae. A total of 489, 444 and 470 genes were upregulated while 347,484 and 443 were downregulated relative to S. pneumoniae in S. pseudopneumoniae, S. oralis and S. mitis respectively. Important findings were the up-regulation of TCS (two component systems) and transposase which were found to be specific to S. pseudopneumoniae.

Conclusions: This study provides insight to the current understanding of the genomic content of $S$. pseudopneumoniae. The comparative transcriptome analysis showed hierarchical clustering of expression data of S. pseudopneumoniae with S. pneumoniae and S. mitis with S. oralis. This proves that transcriptional profiling can facilitate in elucidating the genetic distance between closely related strains.
\end{abstract}

\section{Background}

Streptococcus pseudopneumoniae is a recently described member of the 'S. mitis' group of viridians streptococci, which is phenotypically and genetically close to S. pneumoniae, S. mitis, and S. oralis [1]. S. pseudopneumoniae strains characterized to date has been isolated from the lower respiratory tract [2-4]. This species is known to cause infections in patients having a history of chronic obstructive pulmonary disease or exacerbation of chronic obstructive pulmonary disease $[4,5]$. However, the clinical significance of this species is currently unknown.

Streptococcus pneumoniae is the most common cause of well-defined clinical syndrome of pneumonia, bacterial meningitis, and nongonoccal urethritis in humans [6-8]. By contrast, two medically important 'S. mitis' group

\footnotetext{
* Correspondence: kimwy@cau.ac.kr

${ }^{1}$ Department of Microbiology \& Research Center for Medical Sciences,

Chung-Ang University College of Medicine, Seoul, 156-756, Republic of Korea Full list of author information is available at the end of the article
}

streptococci, S. mitis and S. oralis are recognized as important etiological agents for subacute endocarditis and septicaemia $[9,10]$. Recently, pancreatic cancer has been associated with $S$. mitis, increasing the clinical relevance of this group [11].

The pathogenicity and the underlying genetic identity of S. pseudopneumoniae are not well characterized in relation to its phylogenetic neighbours, S. pneumoniae, $S$. mitis, and S. oralis. Unlike S. pneumoniae, S. pseudopneumoniae is optochin resistant in the presence of $5 \%$ $\mathrm{CO}_{2}$, is bile insoluble, and lacks the pneumococcal capsule $[12,13]$. The use of MLST described in this paper allowed a good differentiation between the species [14]. In clinical studies, the phenotypic characterization of the isolates showed relatedness to the species S. pseudopneumoniae, but genotypically it was difficult to distinguish from its close neighbour S. pneumoniae [1]. Indeed, S. pseudopneumoniae shares over 99\% 16S rRNA gene homology with S. pneumoniae, S. mitis, and S. oralis [15] showing that it has evolved from a common genetic 
ancestor [16-18]. In recent years, several reports have shown that $S$. pneumoniae share genes encoding virulence factors with $S$. mitis and S. oralis, providing suggestive evidence of lateral gene transfer between these species $[19,20]$.

Genotypic characterization of S. pseudopneumoniae in relation to its neighboring members is necessary to increase its clinical relevance. Comparative genomics or transcriptomics based on genome wide microarrays [21], is now the logical approach used to determine interspecies comparisons [22,23]. Since whole-genome sequencing to elucidate the genetic content of a microorganism is considered to be expensive and time consuming, an approach used for the identification of large number of genes without the need for sequencing is the trend in present era. The entire genomes of S. pneumoniae, S. mitis, and S. oralis have been fully sequenced. However, transcriptome has not been studied in these microorganisms to date, which may lead to the identification of unique virulence genes specific to the strain of interest.

Previously, we identified species-specific genes using suppressive subtractive hybridization ( $\mathrm{SSH}$ ), such as the cpsA gene for S. pneumoniae and the rgg gene for S. oralis [24-26]. In the current study, the gene expression of S. pseudopneumoniae is determined and compared with those of S. pneumoniae KCTC $5080^{\mathrm{T}}$, S. mitis KCTC $3556^{\mathrm{T}}$ and $S$. oralis KCTC $13048^{\mathrm{T}}$ by in silico analysis and by in vitro transcriptome microarrays experiments using open reading frame (ORF) microarrays of Streptococcus pneumoniae R6 (GenBank accession number NC_003098) platform.

\section{Results and discussion}

\section{Statistical analysis of microarray experiments}

We compared the expression profiles by hybridization to the immobilized probes on the microarray of S. pneumoniae TIGR4: NC_003028 with the total RNA of S. oralis KCTC $13048^{\mathrm{T}}$, S. mitis KCTC $3556^{\mathrm{T}}$, and S. pseudopneumoniae CCUG $49455^{\mathrm{T}}$. Total RNA from the strains $S$. pneumoniae KCTC $5080^{\mathrm{T}}$, S. mitis KCTC $3556^{\mathrm{T}}$, S. oralis KCTC $13048^{\mathrm{T}}$, and S. pseudopneumoniae CCUG $49455^{\mathrm{T}}$ was hybridized to NimbleGen S. pneumoniae TIGR4: NC_003028 Gene Expression 4x72K microarrays. Each array contains 4 sets of strains, and each strain was compared with each other strains. Interarray correlation values (Range: $-1 \leq r \leq 1$ ) are shown in the upper right panels and pairwise scatter plots of gene expression values $(\log 2)$ are shown in the lower left panels (Figure 1 ). A correlation value close to 1 shows high similarity between samples. This correlation value between strains $S$. oralis-S. mitis was 0.609, S. oralis-S. pneumoniae was 0.365 , S. oralis-S. pseudopneumoniae was 0.375 , S. mitisS. pneumoniae was 0.438 , S. mitis-S. pseudopneumoniae was 0.536 and S. pneumoniae-S. pseudopneumoniae was 0.499 .

\section{Phylogenetic relatedness between streptococcal species}

Based on their overall genomic profiles, there was clear delineation between each Streptococcus species. The hierarchical clustering analysis from a normalized signal grouped the isolates mainly according to their phylogenetic relationship between each Streptococcus species. The clustering of S. mitis, S. oralis and S. pneumoniae, $S$. pseudopneumoniae strains showed two distinct branches, placing them in two separate clades that clearly differentiated each species group (Figure 2). The map shows the expression levels of the 1,123 probes (Figure 3). A total of 444 genes were upregulated (red) and 484 genes were downregulated(green) in $S$. oralis KCTC $13048^{\mathrm{T}}, 470$ genes were upregulated (red) and 443 genes were downregulated (green) in $S$. mitis KCTC $3556^{\mathrm{T}}$ and 489 genes were upregulated (red) and 347 genes were downregulated (green) in S. pseudopneumoniae CCUG $49455^{\mathrm{T}}$ (Figure 3). Red represents high expression; green represents low expression (Figure 4).

\section{Identification of functional genes revealed by transcriptome analysis}

Whole-genome sequence of $S$. pseudopneumoniae (isolate number: IS7493, GenBank accession numbers: CP002925 and CP002926) was done by Shahinas et al. [27]. Their study shows the presence or absence of genes in the whole genome but not the functional analysis of RNA transcripts. In this study, the availability of the complete S. pneumoniae TIGR4: NC_003028 genome [28] allowed for the analysis of S. oralis KCTC $13048^{\mathrm{T}}$ total RNA transscripts.

About 53 genes were up regulated in $S$. oralis KCTC $13048^{\mathrm{T}}$ when compared with other Streptococcus species (Table 1). About 26 genes were identified as hypothetical proteins while the remaining 27 were associated with amino acid biosynthesis, transport and degenerate transposase proteins.

The 37 genes differentially regulated in S. mitis KCTC $3556^{\mathrm{T}}$ were found to function in amino acid biosynthesis, transport and were transposases, including 4'-phosphopantetheinyl transferase, ABC transporter, alcohol dehydrogenase, alkaline amylopullulanase, Smf DNA processing protein, MSM (multiple sugar metabolism) operon regulatory protein, Peptidoglycan GlcNAc deacetylase, Phosphatidate cytidylyltransferase, $\operatorname{Rec} A$ regulator $\operatorname{RecX}$, Transport protein $\operatorname{ComB}$, UDP-galactose 4-epimerase, truncation, as well as other hypothetical proteins (Table 1).

The 117 upregulated genes of S. pseudopneumoniae CCUG $49455^{\mathrm{T}}$, were found to play a role in amino acid biosynthesis and transport, such as ABC transporter ATP- 

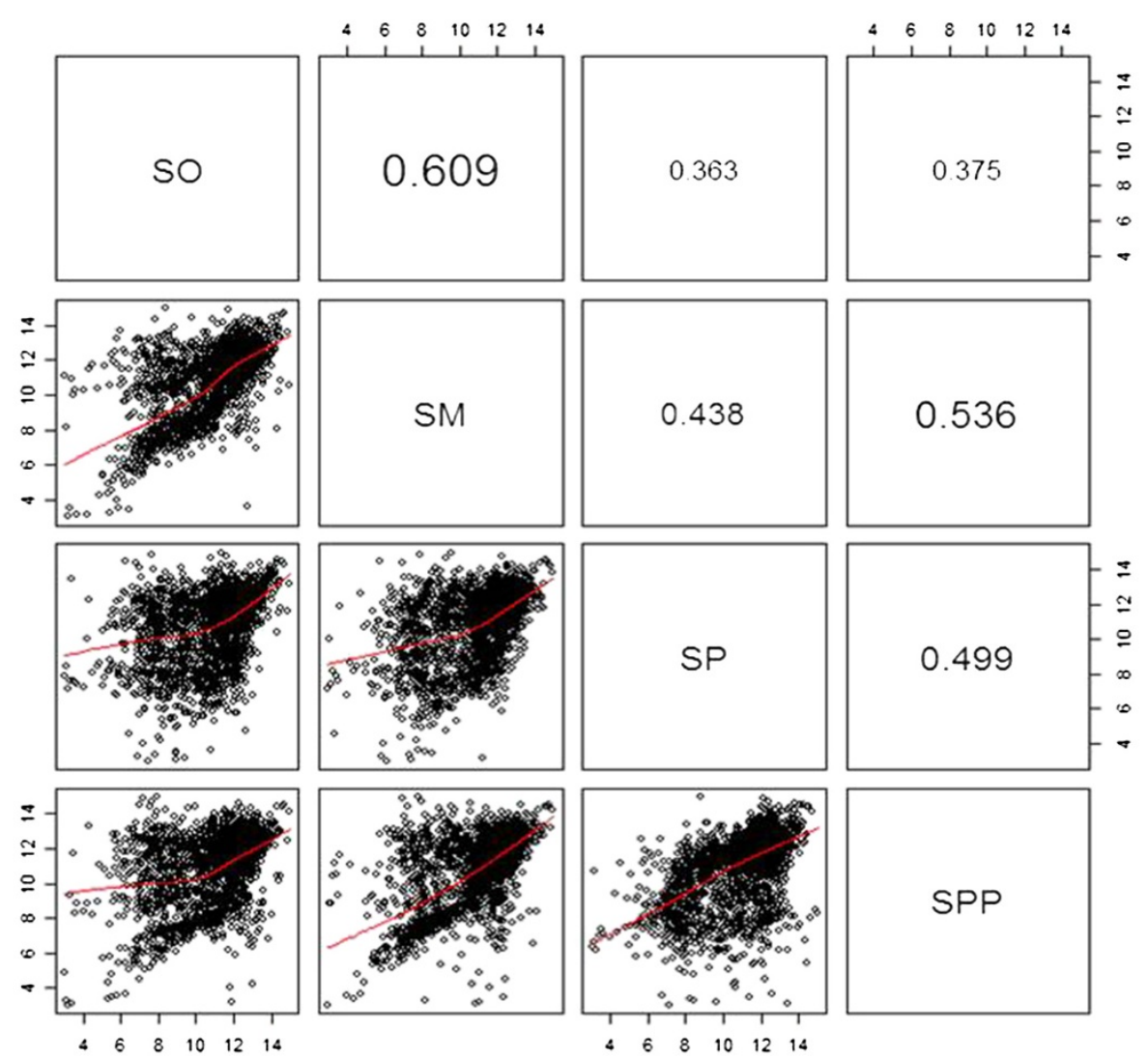

Figure 1 Reproducibility and dynamic range with pairwise scatter plots. Four technical replicates of Streptococcus pseudopneumoniae, Streptococcus pneumoniae, Streptococcus mitis, and Streptococcus oralis RNA were hybridized to NimbleGen Streptococcus pneumoniae R6 Gene Expression $4 \times 72 \mathrm{~K}$ microarrays. Interarray correlation values (Range: $-1 \leq r \leq 1$ ) are shown in the upper right panels and pairwise scatter plots of gene expression values (log2) are shown in the lower left panels. So, S. oralis; Sm, S. mitis; Spp, S. pseudopneumoniae; Sp: S. pneumoniae.

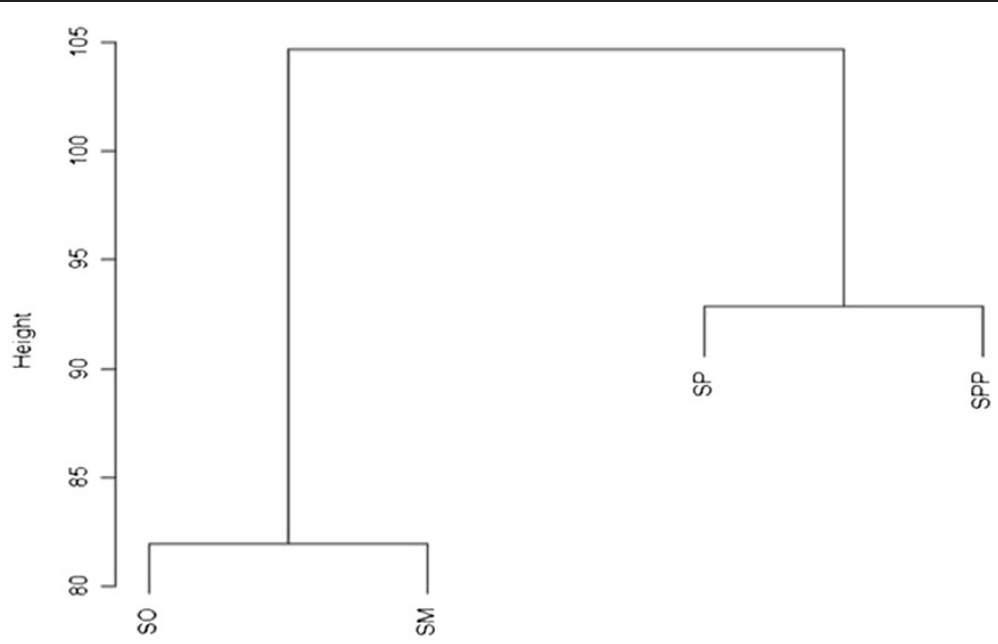

Figure 2 Hierarchical clustering. Phylogenetic relationships of S. mitis, S. oralis, S. pneumoniae, and S. pseudopneumoniae. Each strain formed distinct branch and was placed in a separate two clusters. S. pseudopneumoniae is more closely related to S. pneumoniae. So, S. oralis; Sm, S. mitis; Spp, S. pseudopneumoniae; Sp: S. pneumoniae. 


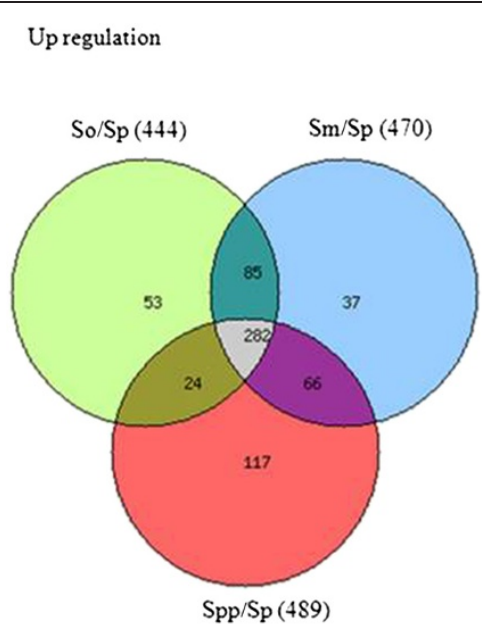

Down regulation

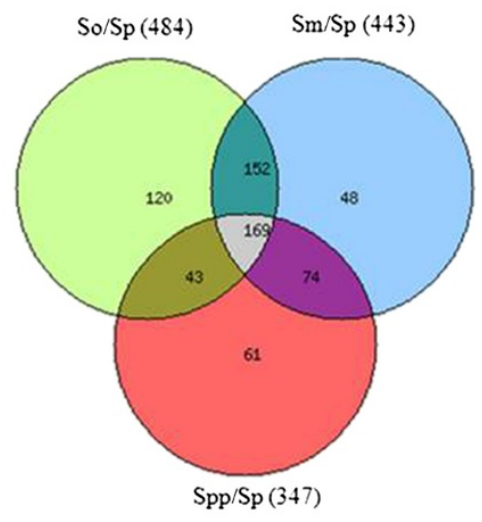

Figure 3 Venn diagram of gene in the viridians group streptococci. So, S. oralis; Sm, S. mitis; Spp, S. pseudopneumoniae; Sp: S. pneumoniae.

binding protein, conserved hypothetical protein, D-alanine glycine permease, histidine kinase, major facilitator superfamily transporter, maltose operon transcriptional repressor, mannitol PTS EII, mannitol-1-phosphate 5-dehydrogenase, mannitol-specific enzyme IIA component, negative regulator of pho regulon for phosphate transport, peptidoglycan GlcNAc deacetylase, phosphotransferase system, positive transcriptional regulator of mutA, response regulator, riboflavin synthase, sortase and transcriptional proteins.

The degenerate transposon was significantly overexpressed in S. pseudopneumoniae compared to its expression in S. oralis and S. mitis. On the other hand, histidine kinase and response regulators associated with the two component system (TCS) were down regulated in the S. oralis and S. mitis (Table 1). Additionally pneumolysin and penicillin-binding protein were also down regulated in S. oralis and S. mitis and showed no signal in the S. pseudopneumoniae.

Upregulation of some interesting genes in the transport group was found in S. pseudopneumoniae like the ATP-binding cassette $(\mathrm{ABC})$ transporters and the two component system (TCS). ABC transporters are integral membrane proteins that actively transport chemically

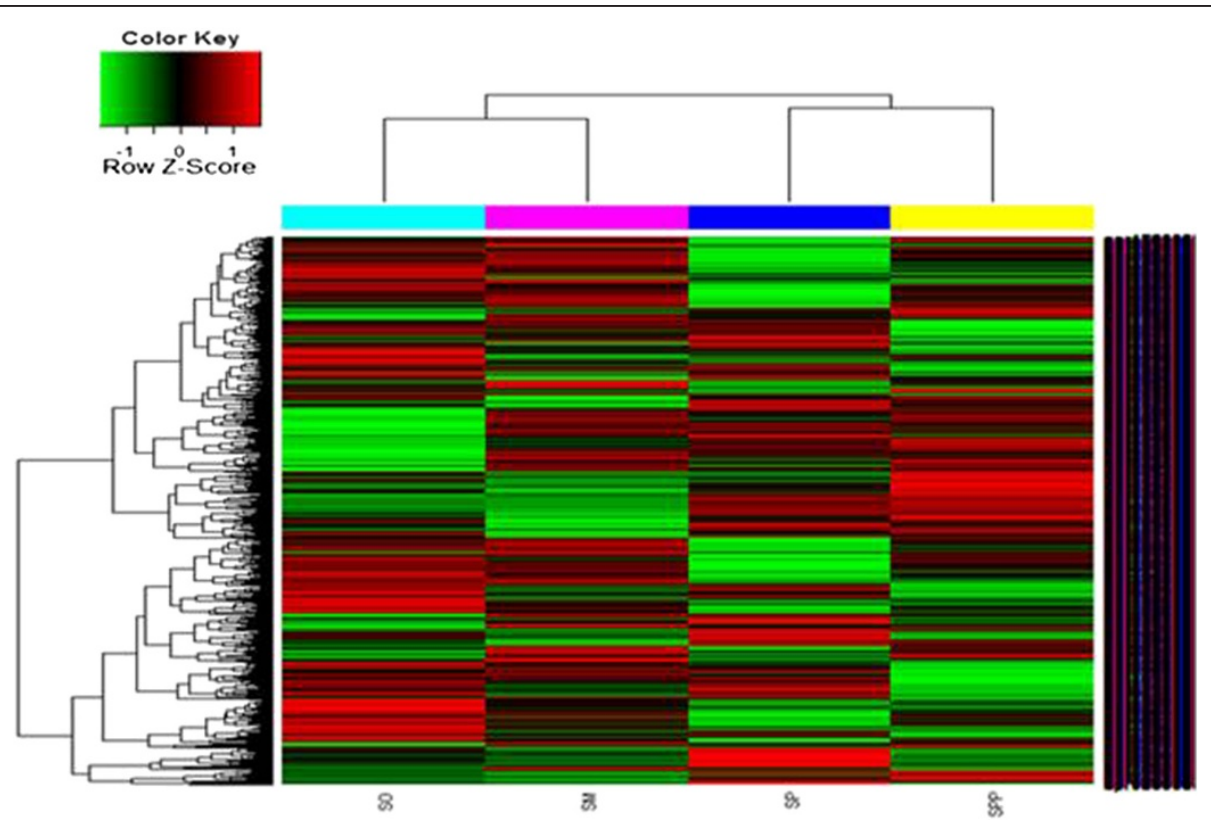

Figure 4 The map of hierarchical clustering of differentially expressed genes. Red represents high expression; green represents low expression. So, S. oralis; Sm, S. mitis; Spp, S. pseudopneumoniae; Sp: S. pneumoniae. 
Table 1 Up regulated genes from the S. oralis, S. mitis, and S. pseudopneumoniae

\begin{tabular}{|c|c|c|c|c|}
\hline Gene name & Function & S. oralis & S. mitis & S. pseudopneumoniae \\
\hline spr1541 & 4'-phosphopantetheinyl transferase & - & 1 & - \\
\hline spr0535 & ABC transporter ATP-binding protein & 6 & 3 & 6 \\
\hline spr0853 & Alanine dehydrogenase & 2 & - & - \\
\hline spr0262 & alcohol dehydrogenase & - & 1 & - \\
\hline spr0247 & Alkaline amylopullulanase & - & 1 & - \\
\hline spr0307 & ATP-dependent protease & 1 & - & - \\
\hline spr1862 & Competence protein & 1 & - & - \\
\hline spr0469 & Conserved hypothetical protein & - & - & 4 \\
\hline spr0369 & D-alanine glycine permease & - & - & 1 \\
\hline spr1563 & Degenerate transposase & 1 & 2 & 11 \\
\hline spr0227 & DEOR-type transcriptional regulator & 1 & - & - \\
\hline spr0347 & DNA alkylation repair enzyme, truncation & 1 & - & - \\
\hline spr1144 & DNA processing Smf protein & - & 1 & - \\
\hline spr1088 & Exodeoxyribonuclease VII small subunit & 1 & - & - \\
\hline spr0136 & Glycosyl transferase, family 2 & 1 & - & - \\
\hline spr1894 & Histidine kinase & - & - & 1 \\
\hline spr1326 & Hypothetical protein & 26 & 23 & 54 \\
\hline spr1453 & Major facilitator superfamily transporter - efflux? & - & - & 1 \\
\hline spr1922 & Maltose operon transcriptional repressor & - & - & 1 \\
\hline spr0356 & Mannitol PTS Ell & - & - & 1 \\
\hline spr0359 & Mannitol-1-phosphate 5-dehydrogenase & - & - & 1 \\
\hline spr0358 & Mannitol-specific enzyme IIA component & - & - & 1 \\
\hline spr0647 & Mannose-6-phosphate isomerase & 1 & - & - \\
\hline spr0696 & Methionine-tRNA ligase & 1 & - & - \\
\hline spr1714 & MSM (multiple sugar metabolism) operon regulatory protein & - & 1 & - \\
\hline spr1323 & NADH oxidase & 1 & - & - \\
\hline spr1899 & Negative regulator of pho regulon for phosphate transport & - & - & 1 \\
\hline spr1095 & O-acetylhomoserine sulfhydrylase, truncation & 1 & - & - \\
\hline spr0127 & orf51 & - & - & 1 \\
\hline spr1333 & Peptidoglycan GlcNAc deacetylase & - & - & 1 \\
\hline spr0241 & Phosphatidate cytidyly|transferase & - & 1 & - \\
\hline spr0562 & Phosphotransferase system sugar-specific Ell component & 2 & - & 1 \\
\hline spr0140 & Positive transcriptional regulator of mutA & - & - & 1 \\
\hline spr1718 & RecA regulator $\operatorname{Rec} X$ & - & 1 & - \\
\hline spr1107 & Response regulator & - & - & 1 \\
\hline spr0164 & Riboflavin biosynthese; a deaminase & - & - & 2 \\
\hline spr0163 & riboflavin synthase subunit alpha & - & - & 1 \\
\hline spr1098 & Sortase & - & - & 1 \\
\hline spr1771 & Subtilisin-like serine protease & 1 & - & - \\
\hline spr1878 & threonine synthase & 1 & - & - \\
\hline spr1051 & TPP-dependent acetoin dehydrogenase alpha chain & 2 & - & - \\
\hline spr0842 & Transposase & - & - & 18 \\
\hline spr1803 & Transcriptional activator & - & - & 1 \\
\hline spr0504 & Transcriptional antiterminator & - & - & 1 \\
\hline spr0044 & Transport protein ComB & - & 1 & - \\
\hline spr1700 & Trehalose operon transcriptional repressor & - & - & 1 \\
\hline spr0362 & trigger factor & 1 & - & - \\
\hline
\end{tabular}


Table 1 Up regulated genes from the S. oralis, S. mitis, and S. pseudopneumoniae (Continued)

\begin{tabular}{|c|c|c|c|c|}
\hline spr0071 & Trk transporter NAD + binding protein $-\mathrm{K}+$ transport & - & - & 1 \\
\hline spr0687 & tRNA (guanine-N(1)-)-methyltransferase & 1 & - & - \\
\hline spr1900 & truncated IS1380-Spn1 transposase & - & - & 1 \\
\hline spr0792 & Type 1 restriction modification system endonuclease $R$ & - & - & 1 \\
\hline spr0790 & Type I restriction modification enzyme methylase subunit & - & - & 1 \\
\hline spr1683 & UDP-galactose 4-epimerase, truncation & - & 1 & - \\
\hline
\end{tabular}

diverse substrates across the lipid bilayers of cellular membranes. This is of clinical importance because multidrug resistance in human cancer cells is mostly the result of the over expression of $\mathrm{ABC}$ transporters that catalyze the extrusion of the cytotoxic compounds used in cancer therapy [29]. Bacterial drug resistance has become an increasing problem. In bacterial cells, $A B C$ transporters are known to contribute to multidrug and antibiotic resistance by extruding drugs or antibiotics [30].

The TCSs of bacteria consist of two proteins, histidine kinase and response regulators, and have received increasing attention for their potential as a novel antibacterial drug targets [31,32]. Some TCSs regulate the expression of antibiotic resistance determinants, including drug-efflux pumps [33]. The overexpression of response regulators of bacterial two-component signal transduction system confers drug resistance by controlling the expression of some drug transporter genes. Various TCSs ubiquitously present in bacteria regulate the transcription of different gene products. The regulation of osmolarity, nutrient uptake, redox potential, sporulation and the expression of virulence factors are under the control of TCSs. The two component system (TCS) serves as a basic stimulus-response coupling mechanism that allows organisms to sense and respond to changes in environmental conditions. The sensor kinase monitors a certain environmental condition and modulates the phosphorylation state of the response regulator that controls genes. One of the most attractive aspects of the TCS is its regulation of antimicrobial resistance factors.

\section{Conclusions}

In summary, based on comparative genomics/transcriptome analysis, using S. pneumoniae as the control strain, facilitated the identification of $S$. pseudopneumoniae transcriptome within streptococci viridans group. We postulate that transcriptional profiling with high statistical power implies the great genetic distance between each streptococci of viridans group. The correlation values by statistical analysis show the closest association between S. oralis and S.mitis. This is also clearly shown by the clustering method which placed S.oralis and $S$. mitis in a separate clade from S.pneumoniae and $S$. pseudopneumoniae revealing their genetic relatedness. Overall expression levels of 489 genes were higher in $S$. mitis strain when compared with the control strain. Some of the important genes identified by functional analysis at RNA level were those belonging to amino acid biosynthesis, transport and degenerate transposase proteins. One of the significant findings in this study was the upregulation of ABC transporters and TCS in S. pseudopneumoniae where the former are known to play a role multi-drug antibiotic resistance and the latter in controlling the virulence factors. Therefore, we conclude by this study that genetic relatedness and pathogenecity in S. pseudopneumoniae in comparison to viridans group was well revealed by transcriptome analysis.

\section{Methods}

Bacterial culture, RNA extraction and CDNA synthesis S. pneumoniae KCTC $5080^{\mathrm{T}}$ was used as the reference strain for comparative microarray experiments with other viridians group of streptococci. S. pneumoniae KCTC $5080^{\mathrm{T}}$, S. pseudopneumoniae CCUG $49455^{\mathrm{T}}, \mathrm{S}$. mitis $\mathrm{KCTC} 3556^{\mathrm{T}}$, and S. oralis $\mathrm{KCTC} 13048^{\mathrm{T}}$ strains were grown on Brain Heart Infusion (BHI) agar (Difco, Detroit, MI, U.S.A.) at $37^{\circ} \mathrm{C}$ for 18 hours. Total RNA was isolated using a RiboPure Bacteria Kit (Ambion, UK) following manufacturer's instructions. Extracted RNA was treated with TURBO DNase (Ambion). RNA quality was checked for purity and integrity as evaluated by OD 260/280 ratio, and analyzed on Agilent 2100 Bioanalyzer (Agilent Technologies, Palo Alto, USA). cDNA was synthesized according to the NimbleGen Expression protocol (Nimblegen, Madison, USA) using the SuperScript double-stranded cDNA synthesis kit (Invitrogen Life Technologies, Carlsbad, CA, U.S.A.). Briefly, $10 \mu \mathrm{g}$ of total RNA was reverse-transcribed to cDNA using an oligo dT primer. Then second-strand cDNA was synthesized. After purification, cDNA was quantified using the ND-1000 Spectrophotometer (NanoDrop, Wilmington, USA).

\section{Labeling and purification}

cDNA was labelled using the One-Color Labelling Kit (Nimblegen) following manufacturer's instructions. $1 \mu \mathrm{g}$ of cDNA samples were labelled with Cy3 using Cy3-random 
nonamer. After purification, the labelled cDNA was quantified using the ND-1000 Spectrophotometer (NanoDrop).

\section{Generation of microarray data}

The Streptococcus pneumoniae R6 microarrays (Nimblegen) were used for the transcriptome analysis. The $S$. pneumoniae R6 microarray contains 2,037 genes: $4 \times 72,000$ probes and 5 replicates (GenBank accession numbers: NC_003098). Labelled cDNA samples of S. pseudopneumoniae, $S$. mitis and $S$. oralis were hybridized onto Nimblegen Expression array (Nimblegen) for $16-20$ hours at $42^{\circ} \mathrm{C}$, according to manufacturer's instructions. Arrays were scanned with a NimbleGen MS 200 Microarray scanner set- at $532 \mathrm{~nm}$ with a resolution of $2 \mu \mathrm{m}$ to produce images in TIFF format according to the manufacturer's instructions. Array data export processing and analysis was performed using NimbleScan (version 2.5). The data discussed in this publication have been deposited in NCBI's Gene Expression Omnibus [34] and are accessible through GEO Series accession number GSE37539 (http://www. ncbi.nlm.nih.gov/geo/query/acc.cgi?acc=GSE37539).

\section{Data acquisition and statistical analysis}

Raw data was extracted using NimbleScan (version 2.5, Gene Expression RMA algorithm). A single raw intensity value was determined for each gene in each array with 2535 genes by taking an average of spot replicates of all 24 probes. Gene signal value was determined by logarithmic transformation (base 2). Statistical significance of the expression data was determined using fold change. Hierarchical cluster analysis was performed using complete linkage and Euclidean distance as a measure of similarity. NimbleScan was used for quantification, image analysis of mRNA data. $R$ scripts (' $R$ ' software) were used for all other analytical process.

\section{Acknowledgements}

This study was supported by a grant of the Korea Healthcare Technology R\&D Project, Ministry for Health \& Welfare, Republic of Korea (A085138).

\section{Author details \\ ${ }^{1}$ Department of Microbiology \& Research Center for Medical Sciences, Chung-Ang University College of Medicine, Seoul, 156-756, Republic of Korea. ${ }^{2}$ Department of Urology, Chung-Ang University College of Medicine, Seoul, 156-756, Republic of Korea.}

\section{Authors' contributions}

WK and SCM contributed to the design of experiments. HKP implemented experiments and drafted the manuscript. WK analyzed results and edited the manuscript. All authors read and approved the final manuscript.

Received: 22 December 2011 Accepted: 18 May 2012

Published: 18 May 2012

\section{References}

1. Arbique JC, Poyart C, Trieu-Cuot P, Quesne G, Carvalho Mda G, Steigerwalt AG, Morey RE, Jackson D, Davidson RJ, Facklam RR: Accuracy of phenotypic and genotypic testing for identification of Streptococcus pneumoniae and description of Streptococcus pseudopneumoniae sp. nov. J Clin Microbiol 2004, 42(10):4686-4696.
2. Carvalho Mda G, Tondella ML, McCaustland K, Weidlich L, McGee L, Maye LW, Steigerwalt A, Whaley M, Facklam RR, Fields B, et al: Evaluation and improvement of real-time PCR assays targeting lyt $A$, ply, and psaA genes for detection of pneumococcal DNA. J Clin Microbiol 2007, 45(8):2460-2466.

3. Cochetti I, Vecchi M, Mingoia M, Tili E, Catania MR, Manzin A, Varaldo PE, Montanari MP: Molecular characterization of pneumococci with effluxmediated erythromycin resistance and identification of a novel mef gene subclass, mef(I). Antimicrob Agents Chemother 2005, 49(12):4999-5006.

4. Keith ER, Podmore RG, Anderson TP, Murdoch DR: Characteristics of Streptococcus pseudopneumoniae isolated from purulent sputum samples. J Clin Microbiol 2006, 44(3):923-927.

5. Harf-Monteil C, Granello C, Le Brun C, Monteil H, Riegel P: Incidence and pathogenic effect of Streptococcus pseudopneumoniae. J Clin Microbiol 2006, 44(6):2240-2241.

6. Marrie TJ, Durant $H$, Yates L: Community-acquired pneumonia requiring hospitalization: 5-year prospective study. Rev Infect Dis 1989, 11(4):586-599.

7. Schmidt A, Bisle B, Kislinger T: Quantitative peptide and protein profiling by mass spectrometry. Meth Mol Biol 2009, 492:21-38.

8. Fine MJ, Smith MA, Carson CA, Mutha SS, Sankey SS, Weissfeld LA, Kapoor WN: Prognosis and outcomes of patients with community-acquired pneumonia. A meta-analysis. JAMA 1996, 275(2):134-141.

9. Dyson C, Barnes RA, Harrison GA: Infective endocarditis: an epidemiological review of 128 episodes. J Infect 1999, 38(2):87-93.

10. Willcox MD, Drucker DB, Hillier VF: In-vitro adherence of oral streptococci in the presence of sucrose and its relationship to cariogenicity in the rat. Arch Oral Biol 1988, 33(2):109-113.

11. Farrell JJ, Zhang L, Zhou H, Chia D, Elashoff D, Akin D, Paster BJ, Joshipura K, Wong DT: Variations of oral microbiota are associated with pancreatic diseases including pancreatic cancer. Gut 2012, 61(4):582-588.

12. Johnston C, Hinds J, Smith A, van der Linden M, Van Eldere J, Mitchell TJ: Detection of large numbers of pneumococcal virulence genes in streptococci of the mitis group. J Clin Microbiol 2010, 48(8):2762-2769.

13. Simoes AS, Sa-Leao R, Eleveld MJ, Tavares DA, Carrico JA, Bootsma HJ, Hermans PW: Highly penicillin-resistant multidrug-resistant pneumococcus-like strains colonizing children in Oeiras, Portugal: genomic characteristics and implications for surveillance. J Clin Microbiol 2010, 48(1):238-246.

14. Do T, Jolley KA, Maiden MCJ, Gilbert SC, Clark D, Wade WG DB: Population structure of Streptococcus oralis. Microbiology 2009, 155:2593-2602.

15. Suzuki N, Seki M, Nakano Y, Kiyoura Y, Maeno M, Yamashita Y: Discrimination of Streptococcus pneumoniae from viridans group streptococci by genomic subtractive hybridization. J Clin Microbio/ 2005, 43(9):4528-4534.

16. Whatmore AM, Efstratiou A, Pickerill AP, Broughton K, Woodard G, Sturgeon D, George R, Dowson CG: Genetic relationships between clinical isolates of Streptococcus pneumoniae, Streptococcus oralis, and Streptococcus mitis: characterization of "Atypical" pneumococci and organisms allied to S. mitis harboring S. pneumoniae virulence factor-encoding genes. Infect Immun 2000, 68(3):1374-1382.

17. Mager DL, Ximenez-Fyvie LA, Haffajee AD, Socransky SS: Distribution of selected bacterial species on intraoral surfaces. J Clin Periodontol 2003, 30(7):644-654

18. Whiley RA, Beighton D: Current classification of the oral streptococci. Oral Microbiol Immunol 1998, 13(4):195-216.

19. Seki M, Yamashita Y, Torigoe H, Tsuda H, Sato S, Maeno M: Loop-mediated isothermal amplification method targeting the lytA gene for detection of Streptococcus pneumoniae. J Clin Microbiol 2005, 43(4):1581-1586.

20. Verhelst R, Kaijalainen T, De Baere T, Verschraegen G, Claeys G, Van Simaey L, De Ganck C, Vaneechoutte M: Comparison of five genotypic techniques for identification of optochin-resistant pneumococcus-like isolates. J Clin Microbiol 2003, 41(8):3521-3525.

21. van Hijum SA, Baerends RJ, Zomer AL, Karsens HA, Martin-Requena V, Trelles O, Kok J, Kuipers OP: Supervised Lowess normalization of comparative genome hybridization data-application to lactococcal strain comparisons. BMC Bioinforma 2008, 9:93.

22. Aguado-Urda M, Lopez-Campos GH, Fernandez-Garayzabal JF, MartinSanchez F, Gibello A, Dominguez L, Blanco MM: Analysis of the genome content of Lactococcus garvieae by genomic interspecies microarray hybridization. BMC Microbiol 2010, 10:79.

23. Fukiya S, Mizoguchi H, Tobe T, Mori H: Extensive genomic diversity in pathogenic Escherichia coli and Shigella strains revealed by comparative genomic hybridization microarray. J Bacterio/ 2004, 186(12):3911-3921. 
24. Park HK, Lee HJ, Jeong EG, Shin HS, Kim W: The rgg gene is a specific marker for Streptococcus oralis. J Dent Res 2010, 89(11):1299-1303.

25. Park HK, Lee HJ, Kim W: Real-time PCR assays for the detection and quantification of Streptococcus pneumoniae. FEMS Microbiol Lett 2010 310(1):48-53.

26. Park HK, Lee SJ, Yoon JW, Shin JW, Shin HS, Kook JK, Myung SC, Kim W: Identification of the $c p s A$ gene as a specific marker for the discrimination of Streptococcus pneumoniae from viridans group streptococci. J Med Microbiol 2010, 59(10):1146-1152.

27. Shahinas D, Tamber GS, Arya G, Wong A, Lau R, Jamieson F, Ma JH, Alexander DC, Low DE, Pillai DR: Whole-genome sequence of Streptococcus pseudopneumoniae isolate IS7493. J Bacterio/ 2011, 193(21):6102-6103.

28. Tettelin H, Nelson KE, Paulsen IT, Eisen JA, Read TD, Peterson S, Heidelberg J, DeBoy RT, Haft DH, Dodson RJ, et al: Complete genome sequence of a virulent isolate of Streptococcus pneumoniae. Science 2001, 293(5529):498-506.

29. Gottesman MM, Ambudkar SV: Overview: ABC transporters and human disease. J Bioenerg Biomembr 2001, 33(6):453-458.

30. Sutcliffe IC, Russell RR: Lipoproteins of gram-positive bacteria. J Bacteriol 1995, 177(5):1123-1128.

31. Macielag MJ, Goldschmidt R: Inhibitors of bacterial two-component signalling systems. Expet Opin Investig Drugs 2000, 9(10):2351-2369.

32. Matsushita M, Janda KD: Histidine kinases as targets for new antimicrobial agents. Bioorg Med Chem 2002, 10(4):855-867.

33. Hirakawa H, Nishino K, Hirata T, Yamaguchi A: Comprehensive studies of drug resistance mediated by overexpression of response regulators of two-component signal transduction systems in Escherichia coli. J Bacteriol 2003, 185(6):1851-1856.

34. Edgar R, Domrachev M, Lash AE: Gene Expression Omnibus: NCBI gene expression and hybridization array data repository. Nucleic Acids Res 2002, 30(1):207-210

doi:10.1186/1471-2180-12-77

Cite this article as: Park et al: Comparative transcriptomic analysis of streptococcus pseudopneumoniae with viridans group streptococci. BMC Microbiology 2012 12:77.

\section{Submit your next manuscript to BioMed Central and take full advantage of:}

- Convenient online submission

- Thorough peer review

- No space constraints or color figure charges

- Immediate publication on acceptance

- Inclusion in PubMed, CAS, Scopus and Google Scholar

- Research which is freely available for redistribution 